\title{
Mechanism of Relaxant Action of Ethyl 6-amino-5-cyano-2-methyl- 4-(pyridin-4-yl)-4H-pyran-3-carboxylate Mainly Through Calcium Channel Blockade in Isolated Rat Trachea
}

\author{
Soledad Alemán-Pantitlán ${ }^{1}$, César Millán-Pacheco ${ }^{1}$, Miguel A. Vázquez ${ }^{2}$, Fernando Hernández-Borja ${ }^{2}$, Rafael \\ Villalobos-Molina ${ }^{3}$, Blanca Bazán-Perkins ${ }^{4}$, Samuel Estrada-Soto ${ }^{1, *}$ \\ ${ }^{1}$ Facultad de Farmacia, Universidad Autónoma del Estado de Morelos, Cuernavaca, Morelos, Mexico, ${ }^{2}$ Departamento de Química, División de Ciencias \\ Naturales y Exactas, Universidad de Guanajuato, Guanajuato, Mexico, ${ }^{3}$ Unidad de Biomedicina, Facultad de Estudios Superiores-Iztacala, Universidad \\ Nacional Autónoma de México, Tlalnepantla, Mexico, ${ }^{4}$ Departamento de Hiperreactividad Bronquial, Instituto Nacional de Enfermedades Respiratorias \\ Ismael Cosío Villegas, Mexico City, Mexico.
}

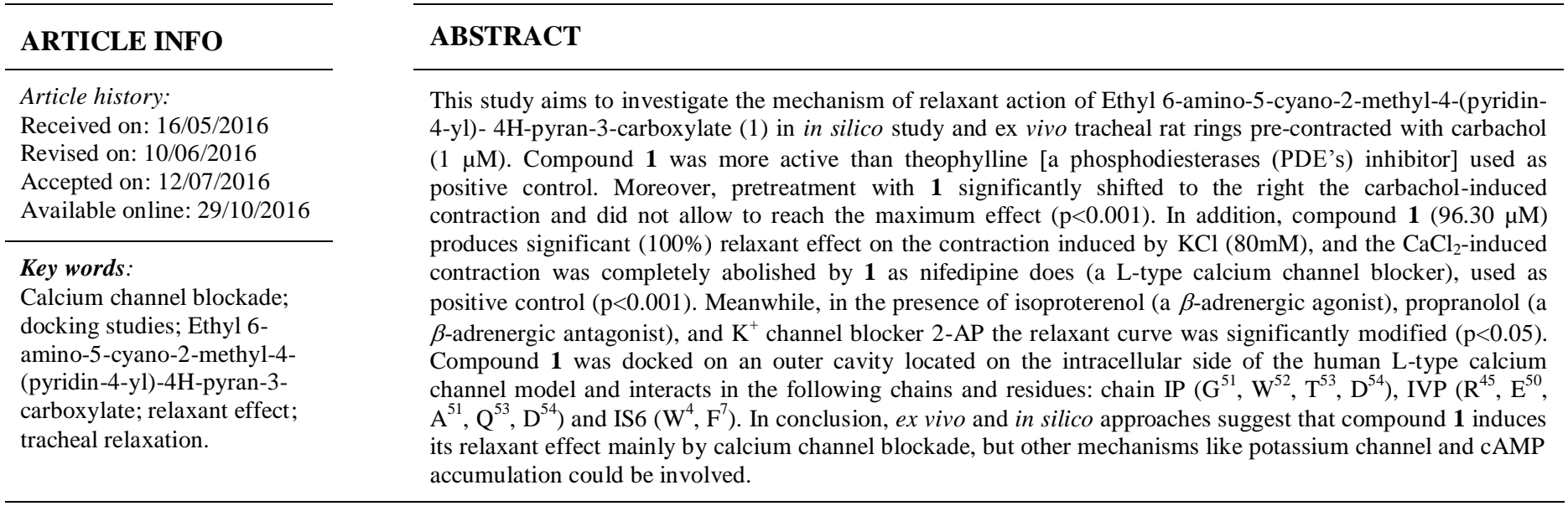

\section{INTRODUCTION}

The increase in intracellular calcium concentration $\left(\left[\mathrm{Ca}^{2+}\right]_{i}\right)$ involves voltage-gated, receptor-operated, store operated, and nonspecific $\mathrm{Ca}^{2+}$-influx, as well as sarcoplasmic reticulum release through channels activated by the phospholipase $\mathrm{C}$ (PLC), inositol trisphosphate $\left(\mathrm{IP}_{3}\right)$ and CD38/ciclyc ADP ribose (cADPR) phathways (Prakash, 2013; Perez-Zoghbi et al., 2009; Sanderson et al., 2008). Then, mechanisms such as the sarcoplasmic reticulum $\mathrm{Ca}^{2+}$-ATPase (SERCA), the bidirectional $\mathrm{Na} / \mathrm{Ca}^{2+}$ exchanger (NCX), and mitochondrial buffering help limit $\left[\mathrm{Ca}^{2+}\right]_{i}$ restore levels after removing the agonist (Mahn et al.,

* Corresponding Author

Email: enoch@ uaem.mx
2010; Perez-Zoghbi et al., 2009). Beyond $\left[\mathrm{Ca}^{2+}\right]_{i}$, the $\mathrm{Ca}^{2+}-$ calmodulin-myosin light chain (MLC) kinase-MLC cascade regulates contractility mediated by actin-miosin interactions (Jude et al., 2008; Berridge 2008). Thus, the regulation of [Ca2+]i in smooth muscle of the airways is a target of interest for research and develop of potential antiasthmatic drugs. Despite the currently available array of antiasmathic therapies, the search for novel chemical entities with new mode of actions, represents an important field of investigation for the development of safely and effectively drugs for the treatment of asthma. In this context, previous research work allowed us to determine the relaxant effect of Ethyl-6-amino-5-cyano-2-methyl-4-(pyridin-4-yl)-4H-pyran-3carboxylate (1, Fig. 1) on rat tracheal smooth muscle, and results indicate that it was 1.5 fold more active than theophylline, used as positive control (Alemán-Pantitlán et al., 2016). 
Furthermore, current work was designed in order to determine the underlying functional mode of action of $\mathbf{1}$ on tracheal rat ring and, by using Docking studies, to explain its interactions with L-type calcium channel.

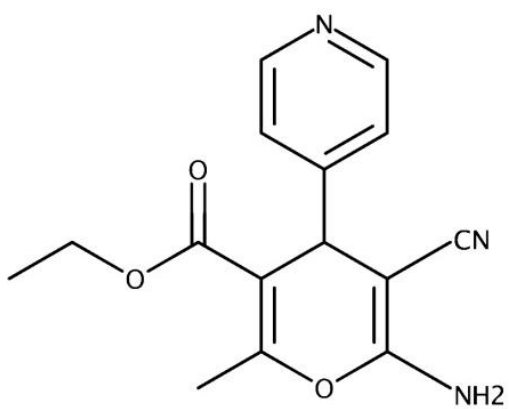

Fig. 1: Chemical structure of compound 1.

\section{MATERIAL AND METHODS}

\section{Chemicals and drugs}

Carbamylcholine chloride (carbachol), theophylline, isoproterenol, potassium chloride $(\mathrm{KCl})$, calcium chloride $\left(\mathrm{CaCl}_{2}\right)$, glibenclamide, 2-aminopyridine, nifedipine and dimethylsulfoxide (DMSO) were purchased from Sigma-Aldrich Co. (St. Louis, MO, US). All other reagents were analytical grade from local sources. Ethyl 6-amino-5-cyano-2-methyl-4-(pyridin-4-yl)-4H-pyran-3carboxylate (1) was previously obtained by synthesis (Hernández et al., 2013).

\section{Animals}

Healthy male Wistar rats (250-300 g) were used and maintained under standard laboratory conditions, with free access to food and water. All animal procedures were conducted in accordance with our Federal Regulations for Animal Experimentation and Care (SAGARPA, NOM-062-ZOO-1999, Mexico), and approved by the Institutional Animal Care and Use Committee based on US National Institute of Health publication (No. 85-23, revised 1985). All experiments were carried out using six animals per group.

\section{Rat tracheal relaxation assay}

Trachea was removed from rats, cleaned out of adhering connective tissue, and cut into $3-5 \mathrm{~mm}$ length rings. Then, tissue segments were mounted by stainless steel hooks under an optimal tension of $2 \mathrm{~g}$, in $10 \mathrm{~mL}$ organ baths containing warmed $\left(37^{\circ} \mathrm{C}\right)$ and oxygenated $\left(\mathrm{O}_{2}: \mathrm{CO}_{2}, 95: 5\right)$ Krebs solution (composition, $\mathrm{mM}$ : $\mathrm{NaCl}, 118 ; \mathrm{KCl}, 4.7 ; \mathrm{CaCl}_{2}, 2.5 ; \mathrm{MgSO}_{4}, 1.2 ; \mathrm{KH}_{2} \mathrm{PO}_{4}, 1.2$; $\mathrm{NaHCO}_{3}, 25.0$; EDTA, 0.026; glucose, 11.1, pH 7.4). Changes in tension were recorded by Grass-FT03 force transducers (Astromed, West Warwick, RI, US) connected to a MP100 analyzer (BIOPAC Instruments, Santa Barbara, CA, US), as described (Sánchez-Recillas et al., 2014a). After equilibration, rings were contracted by carbachol $(1 \mu \mathrm{M})$ and washed every 30 min for $2 \mathrm{~h}$. After pre-contraction with carbachol, the test samples (compound $\mathbf{1}$ and positive control) were added to the bath in a volume of $100 \mu \mathrm{L}$; then cumulative concentration-response curves were obtained for each ring. The relaxant effect of test samples were determined by comparing the muscular tone of the contraction before and after the application of the test materials.

In order to establish the underlying mode of action of $\mathbf{1}$, the following ex vivo experiments were carried out:

a) For the interaction with the cholinergic receptors, concentration response curves (CRC) were obtained with carbachol (0.006-540 $\mu \mathrm{M})$ after tissues were incubated with $1\left(\mathrm{EC}_{50}=96.30 \mu \mathrm{M}\right)$ during $15 \mathrm{~min}$. Carbachol-contractile effect was determined comparing the contraction induced by carbachol in absence and presence of $\mathbf{1}$.

b) For the interaction with phosphodiesterases (PDE's), tissues were incubated with compound $1(96.30 \mu \mathrm{M})$ during $15 \mathrm{~min}$, then theophylline (inhibitor of PDE's) was cumulatively added to the bath $(1.67-550 \mu \mathrm{M})$, and concentration response curves (CRC) were obtained. The relaxant effect induced by theophylline was compared in absence and presence of $\mathbf{1}$.

c) For interaction with $\beta$-adrenergic receptor and cAMP increase, tissues were pre-incubated during 15 min with isoproterenol $(10 \mu \mathrm{M} ; \beta 2$ adrenergic agonist) and propranolol $(10 \mu \mathrm{M} ; \beta$-adrenergic antagonist) and maximal relaxing effect of $\mathbf{1}$ was compared in absence and presence of isoproterenol and propranolol.

d) To establish a possible interaction of $\mathbf{1}$ with L-type calcium channel blockade, the tracheal rings were precontracted with high $\mathrm{KCl}(80 \mathrm{mM})$. Once a plateau was attained, CRC of 1-induced relaxation were obtained by adding cumulative concentrations of compound to the bath.

e) To determine whether the inhibition of extracellular $\mathrm{Ca}^{2+}$ influx was involved in 1-induced relaxation, the experiments were carried out in $\mathrm{Ca}^{2+}$-free $\mathrm{Krebs}$ solution. Tracheal rings were washed with $\mathrm{Ca}^{2+}$-free Krebs solution containing $\mathrm{KCl}(80 \mathrm{mM})(15 \mathrm{~min})$ and the cumulative $\mathrm{CRC}$ for $\mathrm{CaCl}_{2}$ were obtained in the absence of $\mathbf{1}$ (control group) or after 15 min incubation with $1(96.3 \mu \mathrm{M})$. Finally, the contractile effect induced by $\mathrm{CaCl}_{2}$ was compared in absence and presence of $\mathbf{1}$.

f) In order to explore the role of $\mathrm{K}^{+}$channels on -induced relaxation, tracheal rings were preincubated with the $\mathrm{K}^{+}$ channel blocker glibenclamide $(10 \mu \mathrm{M})$ and 2-AP (100 $\mu \mathrm{M})$ for $15 \mathrm{~min}$ before carbachol $(1 \mu \mathrm{M})$ was added, and then $\mathbf{1}$ was added cumulatively.

\section{In silico docking studies}

The model of the L-type calcium channels was performed by Lipkind and Fozzard (2003), and was kindly given by Prof. Mancilla-Percino (Mancilla-Percino et al., 2010). Nifedipine models of ligands and $\mathbf{1}$ were built using Marvin 
Sketch (6.0.0 Marvin, 2013, ChemAxon, http://www.chemaxon.com). The study of molecular coupling (docking) was performed by using Vina Autodock (Trott and Olson, 2010). The channel was centered at $(0,0,0)$ and was used a mesh size of $22.5 \times 22.5 \times 22.5 \AA$ with a space in the mesh of $1 \AA$ and exhaustiveness of 50. The systems were prepared using Pymol (Schrodinger, 2010) and Autodock/Vina for Pymol (Seeliger and Groot, 2010). In an effort to improve the statistics of the result obtained, a thousand independent molecular dockings were made using Autodock Vina. Images were made using VMD (Humphrey et al., 1996) and molecular interactions with LigPlus (Laskowski and Swindells, 2011).

\section{Statistics}

Data were expressed as mean \pm S.E.M. and statistical significance was evaluated by using one-way ANOVA followed by Tukey's test. $P$ values less than 0.05 were considered to denote statistical significance.

\section{RESULT AND DISCUSSION}

Previous results indicate that 1 was one of the most active relaxant compounds of the entire series evaluated (AlemánPantitlán et al., 2016), being two-times most active than theophylline (positive control). Thus, we decided to determine the functional mode of action of compound $\mathbf{1}$ on tracheal rat rings and, by using Docking studies, to explain its interactions with L-type calcium channel in in silico model. Hence, 1-pretreatment significantly shifted to the right $(\mathrm{p}<0.001)$ the carbachol-induced contraction, and did not allow reaching carbachol-induced maximum contraction (Fig. 2), suggesting that $\mathbf{1}$ is acting as a possible functional non-competitive antagonist.

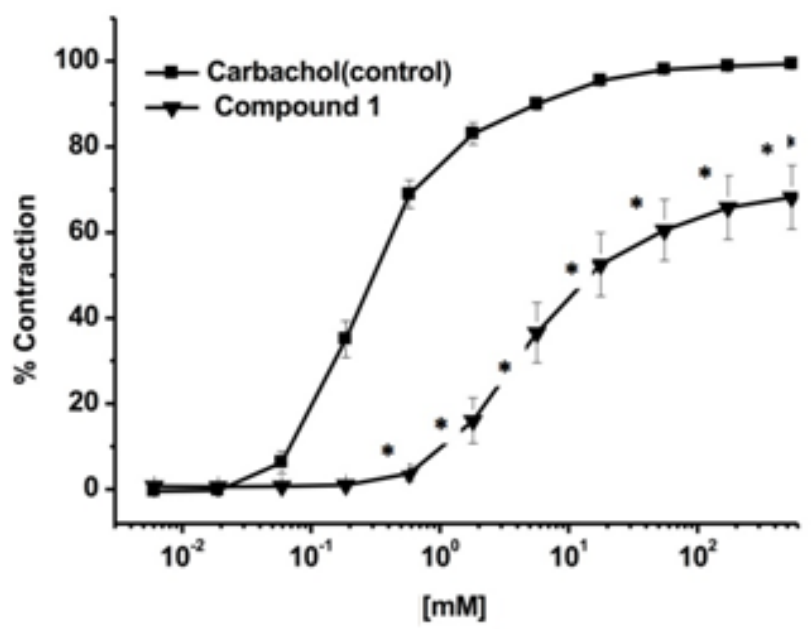

Fig. 2: Inhibitory effect of compound 1 on the concentration-response curve of the contraction induced by carbachol. All results are expressed as the mean \pm S.E.M. of six rats.

In addition, compound $1(1.06-350 \mu \mathrm{M})$ produces significant $(100 \%)$ relaxant effect on the contraction induced by
$\mathrm{KCl}(80 \mathrm{mM})$ (Fig. 3) and the $\mathrm{CaCl} 2$-induced contraction was significantly reduced by compound 1 ( $\mathrm{p}<0.001$ ) (Fig. 4). Thus, Since 1-induced a non-competitive antagonism effect, offers the idea that bioactive $\mathbf{1}$ is not directly interacted with muscarinic receptor (Racké et al., 2006).

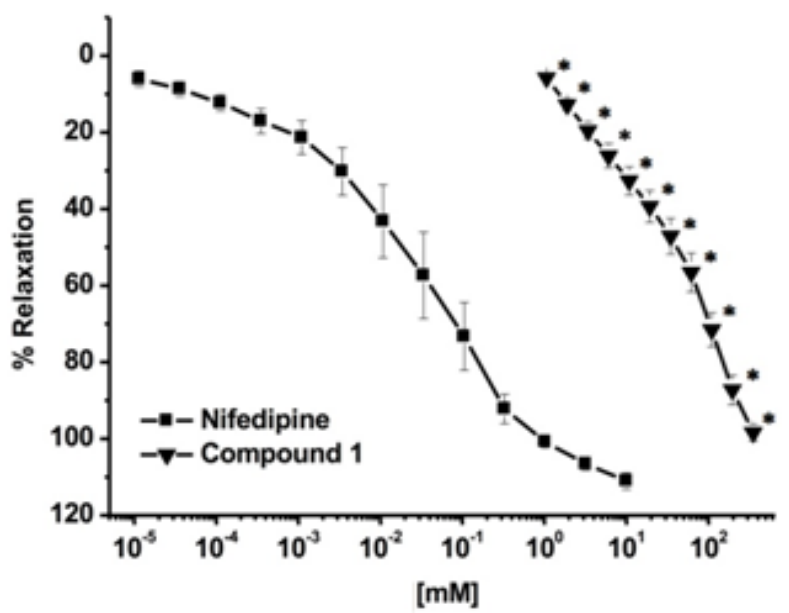

Fig. 3: Relaxant effect of compound 1 on the contraction induced by $\mathrm{KCl}(80$ $\mathrm{mM})$ in rat tracheal rings. Results are presented as mean \pm S.E.M.of six rats

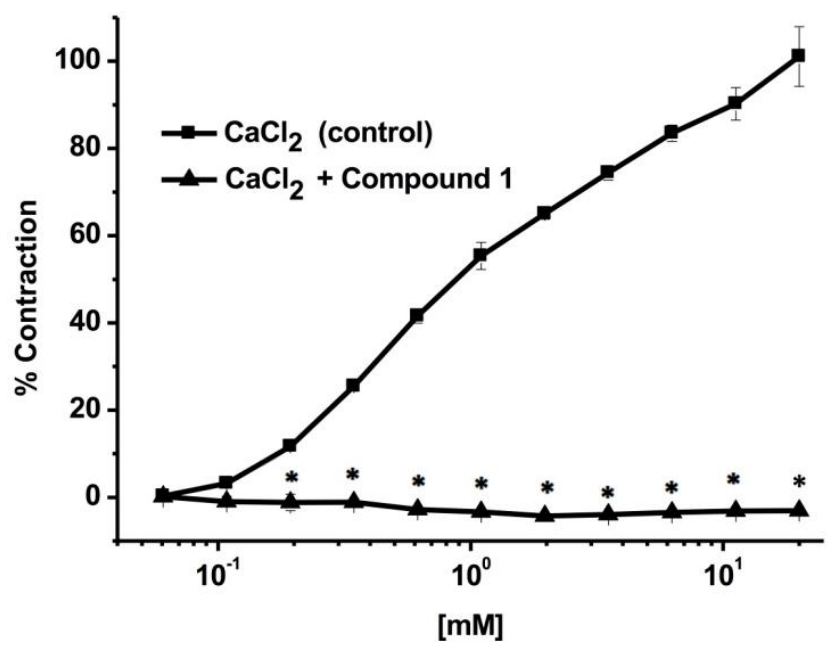

Fig. 4: Inhibitory effect of compound 1 on the cumulative-contraction curve dependent on extracellular $\mathrm{Ca}^{2}+$ influx induced by $80 \mathrm{mM}$ of $\mathrm{KCl}$ in $\mathrm{Ca} 2+$-free solution. Results are presented as mean \pm S.E.M. of six rats.

Meanwhile, the relaxant effect could be produced by blocking a common step which is necessary to produce cholinergic contraction, such as the augment of $\left[\mathrm{Ca}^{2+}\right]_{i}$. It is well known that, in smooth muscle cells, two classes of $\mathrm{Ca}^{2+}$ channels exist: voltage-dependent $\mathrm{Ca}^{2+}$ channels (high $\mathrm{KCl}$ induced contraction is due to membrane depolarization, leading to increased $\mathrm{Ca}^{2+}$ influx through voltage-dependent channels), and receptor operated $\mathrm{Ca}^{2+}$ channels (contraction induced by carbachol in $\mathrm{Ca}^{2+}$ release, through sarcoplasmic reticulum $\mathrm{Ca}^{2+}$ channel activated by $\mathrm{IP}_{3}$ ) (Montaño and Bazan-Perkins, 2005; Siddiqui et al., 2013; Racké et al., 2006). Therefore, our results suggest that 1 induced its relaxant effect by the interference with the $\mathrm{Ca}^{2+}$ influx into the smooth 
muscle cells, since compound $\mathbf{1}$ was capable to relax the contraction induced by $\mathrm{KCl}$ and abolished the $\mathrm{CaCl}_{2}$-induced contraction. Furthermore, we believe that 1 acts as calciumchannel blocker, which result in a decrease in intracellular calcium concentration, and therefore reflected in the relaxation of tracheal smooth muscle (Flores-Soto et al, 2013; Sanchez-Recillas et al., 2014b; Medeiros et al., 2011). On the other hand, in the presence of isoproterenol ( $\beta$-adrenergic agonist) the relaxant curve was significantly displaced to the left $(\mathrm{p}<0.001)$, which indicates a possible synergic effect on $\beta$-adrenergic receptor and/or a potential accumulation of cAMP by guanilate cyclase activation. Likewise, preincubation with propranolol ( $\beta$-adrenergic antagonist) (Fig. 5), also modified the relaxant curve induced by $\mathbf{1}$, corroborating later asseveration (Dowell et al., 2014).

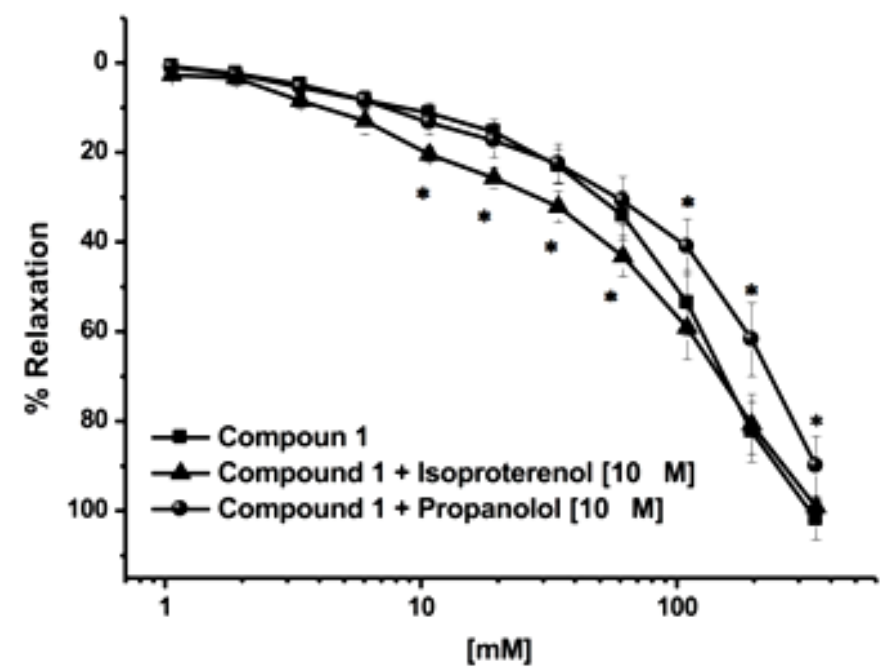

Fig. 5: Effects of isoproterenol $(10 \mu \mathrm{M} ; \beta 2$ adrenergic agonist $)$ and propranolol $(10 \mu \mathrm{M} ; \beta$-adrenergic antagonist) treatments on 1 -induced relaxation in tracheal rings precontracted by carbachol $1 \mu \mathrm{M}$. Results are presented as mean \pm S.E.M. of six rats.

On the other hand, our finding shows that 2-AP $(10 \mu \mathrm{M})$ provokes a shifted to the right the relaxant curve of $1(\mathrm{p}<0.001)$, which suggest a potential potassium channel-opening mode of action. Finally, pre-incubation of glibenclamide $(10 \mu \mathrm{M})$ did not produce any change in the concentration-response relaxant curve induced by 1 (Fig. 6), which allowed us to discard the ATP sensitive potassium channels (KATP) opening in the relaxant effect (Perez-Zoghbi et al., 2009).

In addition, compound $\mathbf{1}$ did not modify the relaxant curve induced by theophylline (Fig. 7), a non-specific inhibitor of phophodiesterases which are responsible for converting cAMP into AMP, suggesting that 1 did not induce an augment of intracellular cAMP as relaxant mechanism of action.

Once the relaxant effect of $\mathbf{1}$ was demonstrated and related with the calcium channel blockade, we decided to investigate the in silico putative interactions of active compound with L-type calcium channel (LTCC). For this, nifedipine (a well know L-type calcium channel blocker) and compound 1 were docked on human LTCC model. In this context, docking results for nifedipine gave four possible sites with different affinity energies ranging from $-6.36+/-0.16$ to $-5.55+/-0.07 \mathrm{kcal} / \mathrm{mol}$. Binding sites and energies are shown in Fig. 8.

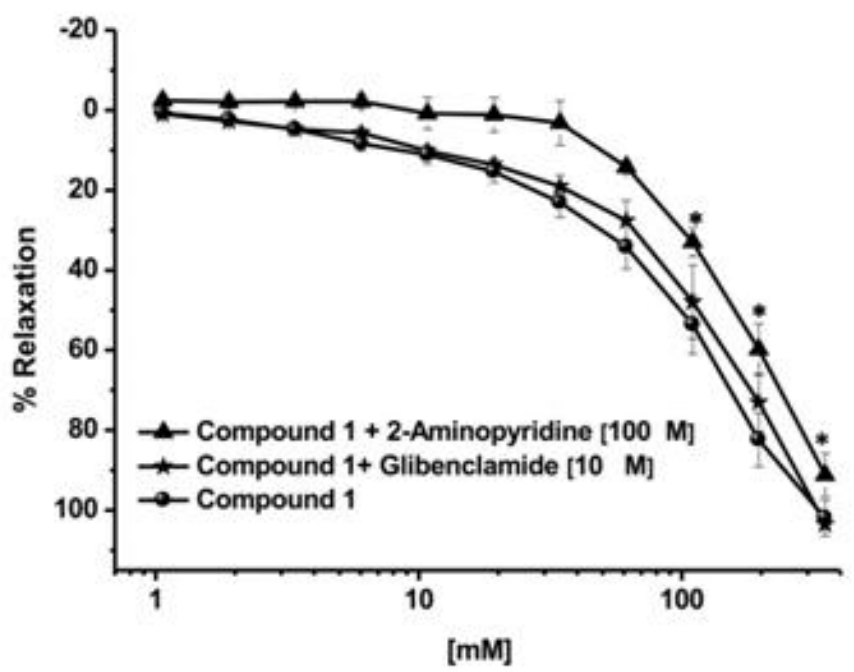

Fig. 6: Effects of glibenclamide $(10 \mu \mathrm{M})$ and 2-AP $(100 \mu \mathrm{M})$ treatments on 1induced relaxation in tracheal rings precontracted by carbachol $1 \mu \mathrm{M}$. Results are presented as mean \pm S.E.M. of six rats.

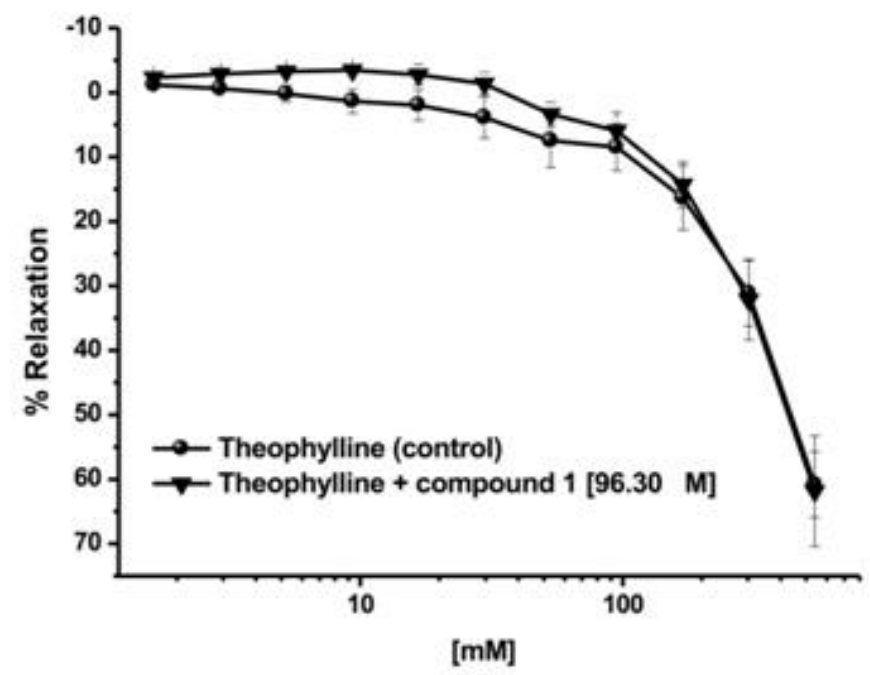

Fig. 7: Effect of compound 1 on the concentration-response curve of the relaxation induced by theophylline. All results are expressed as the mean \pm S.E.M. of six rats

Each binding site was analyzed individually and identifying their corresponding interactions between nifedipine and LTCC model. Fig. 9 shows the structures that were found in each binding site and their interactions. Some of the binding sites calculated in current work were reported previously; however, they were not classified as it was done in this study, as follows: binding site C (Hernández et al., 2013), binding site B (SánchezRecillas et al., 2014b), binding sites B and D (Pandey et al., 2012), and binding site D (Lipkind and Fozzard 2003). 
Even when the energetic differences were small, results showed that nifedipine might be bound in different places for the calcium channel cavities broadening the search for more specific compounds than nifedipine. Lowest affinity energy site is characterized by closed contacts of residues of four distinct chains: $\operatorname{IIIP}\left(\mathrm{F}^{49}, \mathrm{E}^{50}, \mathrm{P}^{53}\right)$, IVP $\left(\mathrm{C}^{46}, \mathrm{~A}^{51}, \mathrm{Q}^{53}, \mathrm{~W}^{52}\right)$, IVS5 $\left(\mathrm{M}^{26}\right)$ and IVS6 $\left(\mathrm{I}^{4}, \mathrm{~F}^{7}, \mathrm{I}^{8}, \mathrm{~F}^{11}\right)$. Only two residues of IVP chain form hydrogen bonds with nifedipine, $\mathrm{E}^{50}$ and $\mathrm{Q}^{53}$, respectively. As noted, Figure 9B showed that no correlation exist between the number of hydrogen bonds created and the affinity energy. Specifically, B5 site interacts with IIIP $\left(\mathrm{F}^{49}, \mathrm{E}^{50}, \mathrm{P}^{53}\right), \mathrm{IVP}\left(\mathrm{I}^{4}, \mathrm{Q}^{50}, \mathrm{~A}^{51}, \mathrm{~W}^{52}, \mathrm{Q}^{53}\right.$, $\left.\mathrm{E}^{54}, \mathrm{C}^{46}\right)$, IVS5 $\left(\mathrm{M}^{26}\right)$ and IVS6 (F7). Taken in account latter results, and by using the same methodology as for nifedipine, it was found that compound $\mathbf{1}$ docked primordially (99.9\%) on a site nearby nifedipine binding sites A and B (Fig. 9). The average affinity energy for 1 was $-6.49+/-0.04 \mathrm{kcal} / \mathrm{mol}$. Binding site and those amino acids interacting with 1 are shown in Fig. 10. In Fig. $10 \mathrm{~B}$ is shown that compound $\mathbf{1}$ is interacting with the calcium channel model in the following chains and residues: chain IP (G51, W52, T53, D54), IVP (R45, E50, A51, Q53, D54), and IS6 (W4, F7). Even when there is only one residue interacting with 1 by hydrogen bond (IVP Q53), the rest of residues interact by van der Waals forces stabilizing the ligand in the calcium channel. Docking results found in this work showed that $\mathbf{1}$ might be able to bind to the calcium channel with a subtle affinity greater than nifedipine does. In conclusion, ex vivo and in silico approaches suggest that compound $\mathbf{1}$ induces its relaxant effect mainly by calcium channel blockade.
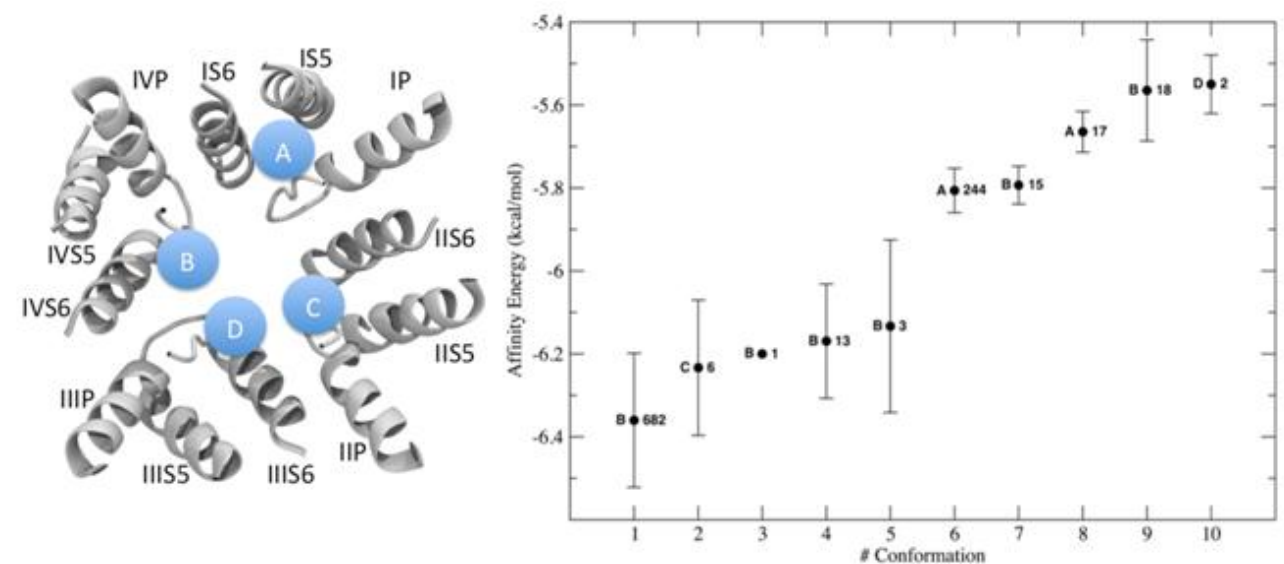

Fig. 8: Binding sites and affinity energies found on 1000 independent docking studies. In the graph, letters on the left side corresp ond to the binding site and the number on the right to the number of conformations found by AutodockVina.

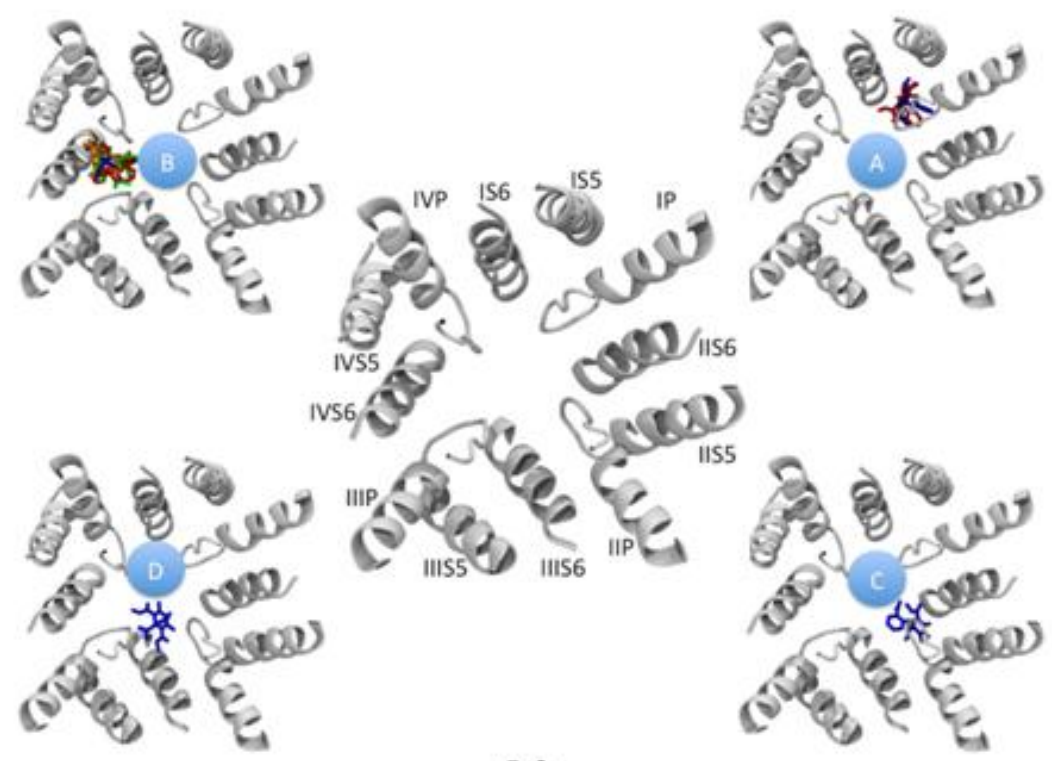

A) 


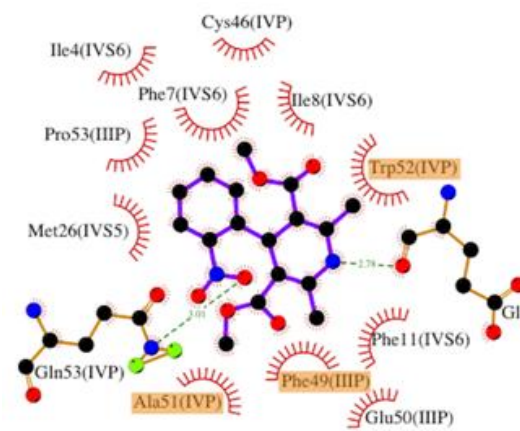

B1 -6.36 (0.2) kcal/mol

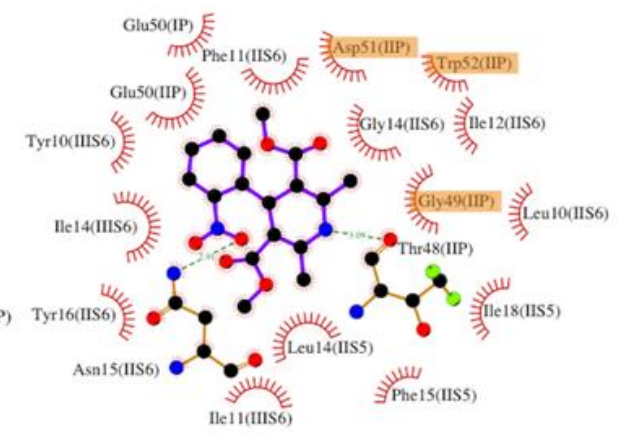

C2 -6.23 (0.2) kcal/mol

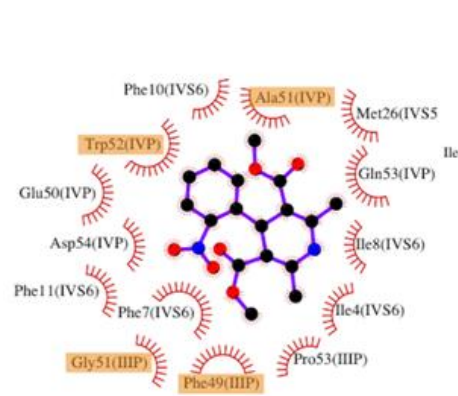

B3 $-6.2 \mathrm{kcal} / \mathrm{mol}$

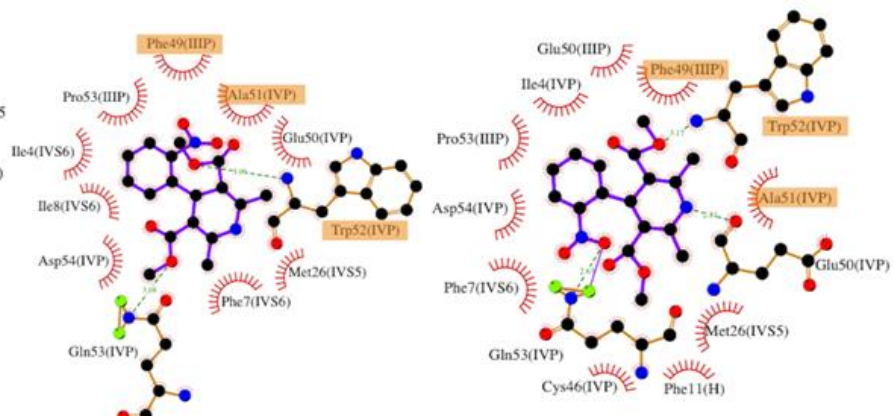

$4-6.17(0.1) \mathrm{kcal} / \mathrm{mol}$

B5 -6.13 (0.2) kcal/mol

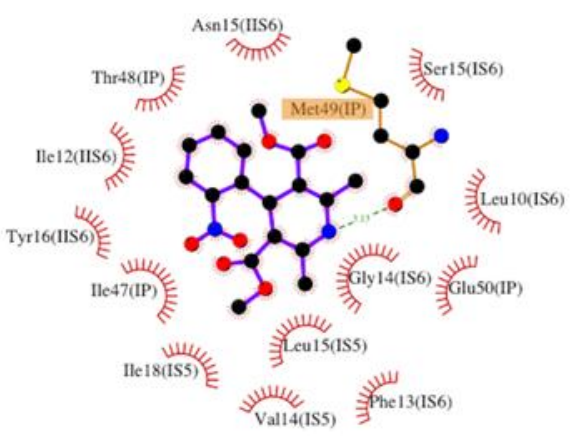

A6 -5.81 (0.1) kcal/mol

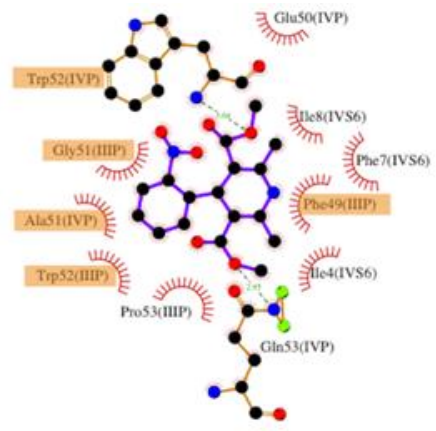

B7 -5.79 (0.1) kcal/mol

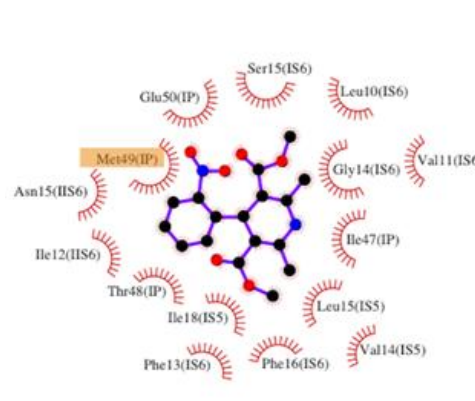

A8 $-5.66(0.1) \mathrm{kcal} / \mathrm{mol}$

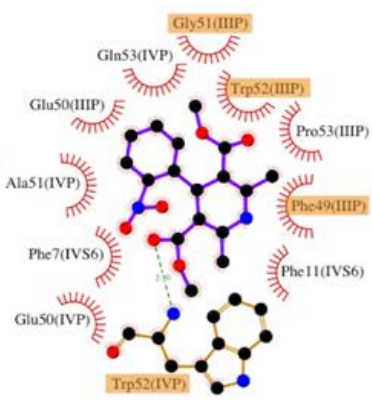

B9 $-5.56(0.1) \mathrm{kcal} / \mathrm{mol}$

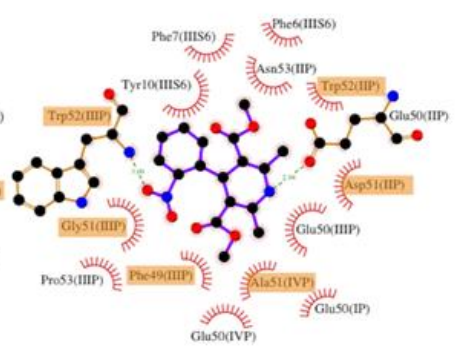

$\mathrm{D} 10-5.55(0.1) \mathrm{kcal} / \mathrm{mol}$

B)

Fig. 9: Binding sites found by AutodockVina for nifedipine and calcium channel studies. A) Binding sites found in current study. B) Nifedipine/calcium channel interactions for each energy group generated by Ligplus (Laskowski and Swindells, 2011). Residues orange highlighted were found previously as disease related by mutagenesis (Pandey et al., 2012). Letter corresponds to the binding site and the number to the conformation in the plot in Fig. 8 . The standard deviation for each conformation is in parenthesis. 

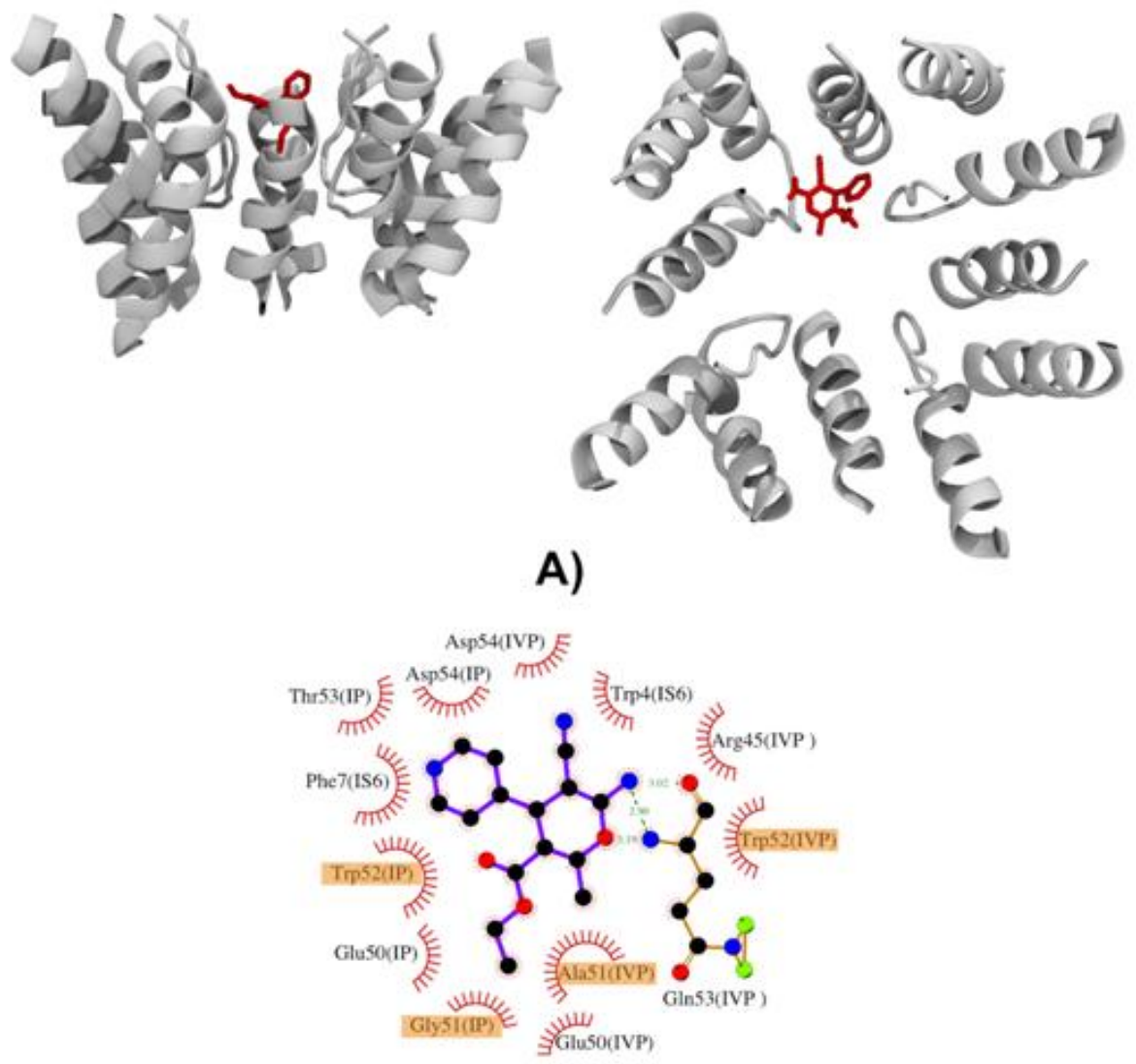

B)

Fig. 10: Compound 1 binding site in the calcium channel model. A) Compound 1 binding site in the same orientation used in Figure 8. B) Compound 1 interactions found in current work. The notation is the same as Figure 9.

\section{ACKNOWLEDGMENTS}

Financial support and sponsorship: This work was partially supported by SEP-CONACyT (Proyecto de Ciencia Básica CB2011-01 No.167044), and Faculty of Pharmacy Budgets (2014 and 2015). S. Alemán-Pantitlán acknowledges the scholarship awarded by CONACyT (267615) for her Ph. D. studies. Finally, S. EstradaSoto is grateful for the fellowship grant from CONACyT (265462) to develop his sabbatical stay at UBIMED, FES Iztacala, UNAM

Conflict of Interests: There are no conflicts of interest.

\section{REFERENCES}

Alemán-Pantitlán S, Estrada-Soto S, Vázquez MA, HernándezBorja F, Alcaraz Y, Villalobos-Molina R, Bazan-Perkins B. Design, synthesis and ex vivo relaxant activity of 3-cyano-2-pyridone and $4 \mathrm{H}$ pyrane derivatives. Lett Drug Des Discov, 2016. (under revision).

Berrigge MJ. Smooth muscle cell calcium activation mechanism. J Physiol, 2008; 586:5047-5061.

Dowell ML, Lavoie TL, Solway J, Krishnan R. Airway smoth muscle: a potential target for asthma therapy. Curr Opin Pulm Med, 2014; 20:66-72.

Flores-Soto E, Reyes-Garcia J, Sommer B, Montaño LM. Sarcoplasmic reticulum $\mathrm{Ca}^{2+}$ refilling is determined by L-type $\mathrm{Ca}^{2+}$ and store operated $\mathrm{Ca}^{2+}$ channels in guinea pig airway smooth muscle. Eur $\mathrm{J}$ Pharmacol, 2013; 721(1-3):21-28.
Hernández F, Sánchez A, Rendón-Vallejo P, Millán-Pacheco C Alcaraz Y, Delgado F, Vázquez MA, Estrada-Soto S. Synthesis, ex vivo and in silico studies of 3-cyano-2-pyridone derivatives with vasorelaxant activity. Eur J Med Chem, 2013; 70:669-676.

Humphrey W, Dalke A, Schulten K. VMD: Visual molecular dynamics. J Mol Graph., 1996; 14: 33-38.

Jude JA, Wylam ME, Walseth TF, Kannan MS. Calcium signaling in airway smooth muscle. Proc Am ThoracSoc, 2008; 5:15-22.

Laskowski RA, Swindells MB. LigPlot+:Multiple LigandProtein Interaction Diagrams for Drug Discovery. J ChemInfModel, 2011; 51:2778-2786.

Lipkind GM, Fozzard HA. Molecular modeling of interactions of dihydropyridines and phenylalkylamines with the inner pore of the Ltype $\mathrm{Ca}^{2+}$ channel. Mol Pharmacol, 2003; 63:499-511.

Mahn K, Ojo OO, Chadwick G, Aaronson PI, Ward JP, Lee TH. $\mathrm{Ca}^{+2}$ homeostasis and structural and functional remodeling of airway smooth muscle in asthma. Torax, 2010; 65:547-55.

Mancilla-Percino T, Correa-Basurto J., Trujillo-Ferrara J, Ramos-Morales FR, Acosta-Hernández ME, Sánchez JS, Saavedra-Velez M. Molecullar modeling study of isoindolines as L-type $\mathrm{Ca}^{+2}$ channel blockers by docking calculations. J Mol Model, 2010; 16:1377-1383.

Montaño LM, Bazán-Perkins B. Resting calcium influx in airway smooth muscle. Can J PhysiologyPharmacol, 2005;83(8-9):717-23.

Medeiros MAA, Pinho JF, De-Lira DP, Barbosa.Fhilo JM Araújo DAM, Cortes SF, Lemos VS, Cruz JS. Curine a bisbenzylisoquinoline alkaloid, blocks L-type $\mathrm{Ca}^{2+}$ channels and decreased intracellular $\mathrm{Ca}^{2+}$ transients in A7r5 cell. Eur J Pharmacol, 2011; 669:100-107.

Pandey APJ, Tripathi S, Gopi Mohan C. Harnessing Human Ntype $\mathrm{Ca}_{2}{ }^{+}$Channel Receptor by Identifying the Atomic Hotspot Regions 
for Its Structure-Based Blocker Design. Molecular Informatics, 2012;31(9):643-657.

Perez -Zoghbi JF, Karner C, Ito S, Shepherd YAA. Sanderson MJ. Ion channel regulation of intracellular calcium and airway smooth muscle function. Pulm Pharmacol Ther, 2009; 22:338-397

Prakash YS. Airway smoth muscle in airway reactivity and remodeling: what have we learned?. Am J Physiol Lung Cell MolPhysiol, 2013; 305:912-933.

Racké K, Juergens UR, Matthiesen S. Control by cholinergic mechanisms. Eur J Pharmacol, 2006; 533:57-68.

Sánchez-Recillas A, Navarrete-Vázquez G, Hidalgo-Figueroa S, Rios MY, Ibarra-Barajas M, Estrada-Soto S. Semisynthesis, ex vivo evaluation, and SAR studies of coumarin derivates as potential antiasthmatic drugs. Eur J Med Chem, 2014; 77:400-408 (a).

Sánchez-Recillas A, Navarrete-Vázquez G, Millán-Pacheco C, Aguilar-Guadarrama B, Ortiz-Andrade R, Estrada-Soto S. Relaxant effect of 7-ethoxy-4-methyl-2H-chromen-2-one by calcium channel blockade: computational and ex vivo studies. J App Pharm Sci, 2014; 4:46-51 (b).

Sanderson MJ, Delmotte P, Bai Y, Perez-Zogbhi JF. Regulation of airway smooth muscle cell contractility by $\mathrm{Ca}^{2+}$ signaling and sensitivity. Proc Am ThoracSoc, 2008; 5:23-31.

Schrödinger L. The PyMol Molecular Graphics System,

Version 1.3r1. 2010
Seelinger D. Groot BL de. Ligand docking and binding site analysis with PyMol and AutoDock /Vina. J Comput Aided Mol Des, 2010; 24:417-422.

Siddiqui S, Redhu NS, Ojo OO, Liu B, Irechukwu N, Billington C, Janssen L, Moir LM. Emerging airway smooth muscle targets to treat asthma. Pulm Pharmacol Ther, 2013; 26:132-144.

Trott O, Olson AJ. AutoDockVina: Improving the speed and accuracy of docking with a new scoring function, efficient optimization, and multithreading. J Comput Chem, 2010; 31:455-461.

\section{How to cite this article:}

Alemán-Pantitlán S, Millán-Pacheco C, Vázquez MA, HernándezBorja F, Villalobos-Molina R, Bazán-Perkins B, Estrada-Soto S. Mechanism of Relaxant Action of Ethyl 6-Amino-5-Cyano-2Methyl-4-(Pyridin-4-Yl)-4h-Pyran-3-Carboxylate Mainly Through Calcium Channel Blockade in Isolated Rat Trachea. J App Pharm Sci, 2016; 6 (10): 029-036. 